\title{
Preparation and characterization of MCM-41-supported hydroxo-bridged dicupric-phenanthroline complex
}

\author{
She-Tin Wong a, Chia-Hung Lee ${ }^{\mathrm{a}}$, Tien-Sung Lin ${ }^{\mathrm{b}}$, Chung-Yuan Mou ${ }^{\mathrm{a}, *}$ \\ ${ }^{a}$ Department of Chemistry, National Taiwan University, Taipei 106, Taiwan \\ b Department of Chemistry, Washington University, St. Louis, MO 63130, USA
}

Received 25 April 2004; revised 15 July 2004; accepted 20 July 2004

Available online 25 September 2004

\begin{abstract}
We have succeeded in preparing a MCM-41-supported hydroxo-bridged dicupric-phenanthroline complex (HPC) via a simple and direct ion-exchanged method. We have studied HPC in two MCM-41 mesoporous forms: tubular $\left(\mathrm{M}_{\mathrm{T}}\right)$ and particulate $\left(\mathrm{M}_{\mathrm{P}}\right)$. The results of a TGA study revealed that most of the HPC in HPC-M $\mathrm{M}_{\mathrm{T}}$ is present inside the channels of the tubular form. The dicupric center of HPC was confirmed by the results of electron paramagnetic resonance (EPR) and extended X-ray absorption fine structure (EXAFS), and the Cu-O-Cu distance of $3.54 \AA$ is close to that of hemocyanin. UV-vis study of this compound also showed the presence of $\mathrm{OH}^{-} \rightarrow \mathrm{Cu}^{2+} \mathrm{charge}^{-t r a n s f e r}$ bands. In addition, $\mathrm{X}$-ray absorption near-edge structure (XANES) results further support the presence of a bridging ligand between the two cupric centers by showing a higher $\mathrm{Cu}-K$-edge $1 \mathrm{~s} \rightarrow 4 \mathrm{~s}$ transition energy than the monocupric zeolite $\mathrm{Y}(\mathrm{Cu}-\mathrm{Y})$. Most interestingly, the HPC complex in HPC-M can undergo reversible transformation from bridging to nonbridging states as revealed in the EPR studies. The initial rate of HPC-M $\mathrm{M}_{\mathrm{T}}$ catalyst in benzyl alcohol oxidation is higher than that of HPC-M which contains a large proportion of monocupric complex in the channels. It seems that the monocupric complex is less active than HPC. Based on the EPR studies, we ascribed the higher activity of HPC-M $\mathrm{M}_{\mathrm{T}}$ to the formation of bridging hydroperoxo species through the interaction between HPC and tert-butyl hydrogen peroxide (TBHP). (C) 2004 Elsevier Inc. All rights reserved.
\end{abstract}

\section{Introduction}

Metal complexes containing porphyrin, salen, and phthalocyanin ligands are frequently used in oxidation and hydroxylation reactions as chemical models to mimic enzymes [1-4]. A recent trend of research in biomimetic study is to immobilize these organometallic complexes onto a solid

Abbreviations: AlMCM-41, aluminum-containing MCM-41; PN, phenanthroline; HPC, hydroxo-bridged dicupric-phenanthroline complex; $\mathrm{M}_{\mathrm{T}}, \mathrm{MCM}-41$ in tubular form; $\mathrm{M}_{\mathrm{P}}, \mathrm{MCM}-41$ in particulate form; $\mathrm{HPC}-\mathrm{M}_{\mathrm{T}}$, HPC in tubular AlMCM-41 by ion-exchange method; HPC-MP, HPC in particulate AlMCM-41 by ion-exchange method; HPC/MPS, HPC in pure silica form of particulate MCM-41 by impregnation method; $\mathrm{PN}+\mathrm{CuM}_{\mathrm{T}}$, phenanthroline adsorption in copper-exchanged tubular AlMCM-41; PN + CuY, phenanthroline adsorption in copper-exchanged zeolite Y; TBHP, tert-butyl hydrogen peroxide.

* Corresponding author. Fax: +886223660954.

E-mail address: cymou@ntu.edu.tw (C.-Y. Mou). support. It is anticipated that this immobilization process will make the catalyst easier to handle especially during separation from the liquid medium. Besides, the support might also play certain roles in stabilizing the catalytic activity and/or modifying the chemoselectivity, regioselectivity, and shape selectivity of the catalyst.

Our long-term research interest is to mimic enzymes, especially hemocyanin which acts as an $\mathrm{O}_{2}$ carrier in mollusk and arthropod. Deoxyhemocyanin has dicuprous active centers and the two coppers are oxidized to the cupric state upon binding $\mathrm{O}_{2}$ as peroxide [5,6]. Normally, biomimetic studies in this area involved the synthesis of dicuprousorgano complexes and subsequently interact with molecular $\mathrm{O}_{2}$ at low temperatures [7-9]. However, this approach may prove to be difficult for the preparation of supported catalysts with the complex immobilized inside the pore structure of porous materials. Accordingly, we devised a more direct method involving the hydroxo-bridged dicupric com- 
plex with ionic character which can be used as precursor for oxyhemocyanin [10]. This complex can be easily introduced into the porous supports via conventional techniques such as impregnation and ion exchange. Recently, the preparation of biomimetic enzymes with dicupric centers on porous support by an adsorption technique has been reported [11].

In this paper, we report the preparation of a hydroxobridged dicupric-phenanthroline complex (HPC), [(PN) $)_{2}$ $\left.\mathrm{Cu}-\mathrm{OH}-\mathrm{Cu}(\mathrm{PN})_{2}\right]^{3+}$ (PN, phenanthroline), supported on the mesoporous aluminosilicate AlMCM-41 via an ionexchange method. We also demonstrated that HPC-like complex can be introduced indirectly into MCM-41 via a twostep adsorption method. We studied the properties of HPC by various spectroscopic methods: (a) XANES and EXAFS for the information regarding the electronic state of the cupric center and its radial distribution; (b) EPR to examine the superexchange interaction in the dicupric centers and the reversible formation of bridging ligands; and (c) UV-vis to examine the electronic transitions. We compared these spectroscopic observations with the known properties of hemocyanin. We further carried out a catalytic reaction to investigate the possible role of bridging ligand in the oxidation of benzyl alcohol with TBHP [12]. Particular attention has been focused on the effect of the space confinement and surface charge of MCM-41 on the stability of HPC.

\section{Experimental}

\subsection{Synthesis}

Three methods were used to prepare various supported phenanthroline-cupric complexes.

\subsubsection{Ion-exchange method}

An exchange solution containing HPC was first prepared according to the method of Haddad et al. [10]. Stoichiometric amounts of cupric chloride dihydrate (abbreviated as $\mathrm{CCD}$ ) and phenanthroline were used. Normally, $100 \mathrm{ml}$ of $\mathrm{H}_{2} \mathrm{O}$ contained $1.6 \mathrm{mmol}$ of $\mathrm{CCD}$ and $3.2 \mathrm{mmol}$ of 1,10 phenanthroline. About $1 \mathrm{~g}$ of the sodium form of AlMCM$41(\mathrm{Si} / \mathrm{Al} \approx 33)$ was then added to $32 \mathrm{ml}$ of the exchange solution and stirred at room temperature for nearly 1.5 days. The solid was then separated by filtration, washed with $200 \mathrm{ml}$ of $\mathrm{H}_{2} \mathrm{O}$, and dried at $373 \mathrm{~K}$. The final product is denoted hereafter as HPC-M $\mathrm{M}_{\mathrm{P}}$ or HPC-M $\mathrm{M}_{\mathrm{T}}$, where the subscripts $\mathrm{P}$ and $\mathrm{T}$ denote particulate and tubular morphologies of AlMCM-41, respectively.

\subsubsection{Impregnation method}

The preparation procedure for this method is similar to the ion-exchange method except that pure silica MCM41 was used. The final product is denoted hereafter as HPC/MPS, where the subscript S denotes pure silica framework.

\subsubsection{Adsorption method}

$\mathrm{Cu}-\mathrm{M}_{\mathrm{T}}$ and $\mathrm{Cu}-\mathrm{Y}$ zeolite were first prepared by ionexchanging $\mathrm{Na}-\mathrm{M}_{\mathrm{T}}$ (twice) and $\mathrm{NH}_{4}-\mathrm{Y}$ (three times), respectively, with a large excess of CCD solution. The solids were then washed twice with $100-150 \mathrm{ml} \mathrm{H}_{2} \mathrm{O}$ and dried at $373 \mathrm{~K}$.

In the case of phenanthroline adsorption on $\mathrm{Cu}-\mathrm{M}_{\mathrm{T}}$, about $1 \mathrm{~g}$ of $\mathrm{Cu}-\mathrm{M}_{\mathrm{T}}$ was added to $33 \mathrm{ml}$ of $95 \%$ ethanolic solution of the ligand $(1.1 \mathrm{mmol})$ and the mixture was stirred at room temperature for 1.5 days. In the case of phenanthroline adsorption on $\mathrm{Cu}-\mathrm{Y}$, about $2 \mathrm{~g}$ of $\mathrm{Cu}-\mathrm{Y}$ was added to $30 \mathrm{ml}$ of $95 \%$ ethanolic solution of the ligand $(0.6 \mathrm{mmol})$ and the mixture was refluxed for 1.5 days. The filtered solids were washed successively with $\mathrm{H}_{2} \mathrm{O}(100-200 \mathrm{ml})$ and $95 \%$ ethanol $(50-100 \mathrm{ml})$ and dried at $373 \mathrm{~K}$. The final product is denoted hereafter as $\mathrm{PN}+\mathrm{CuM}_{\mathrm{T}}$ and $\mathrm{PN}+\mathrm{CuY}$ for MCM41 and zeolite $\mathrm{Y}$ supports, respectively.

\subsection{Characterization techniques}

Nitrogen and carbon contents of the sample were analyzed with a Perkin-Elmer CHN-2400 instrument. Copper and aluminum contents of the sample were analyzed with a simultaneous ICP-AES allied analytical system (Jarrel-Ash, Model ICAP 9000). The powder X-ray diffraction (XRD) patterns were recorded on nonoriented samples with a Scintag $\mathrm{X} 1$ diffractometer using copper $K \alpha$ radiation. Thermogravimetric analysis (TGA) was carried out on a Dynamic TA 2950 thermogravimetric analyzer. The analysis was monitored and controlled by an on-line computer system. The heating rate was $10 \mathrm{~K} \mathrm{~min}^{-1}$ and the carrier gas (air) flow rate was $60 \mathrm{ml} \mathrm{min}^{-1}$. UV-vis spectra were taken on a Hitachi U-3010 spectrophotometer equipped with an integrating sphere to collect the reflected light. A Bruker EMX EPR spectrometer (X-band) was employed to measure the electron paramagnetic resonance (EPR) spectra of the sample. The powdered sample used for the analysis was introduced in a quartz tubing of $4 \mathrm{~mm}$ o.d. The spectrometer is equipped with a variable temperature controller, which allows us to record the spectrum at low temperatures. Typical spectrometer settings are microwave frequency, $9.54 \mathrm{GHz}$; microwave power, $2 \mathrm{~mW}$; modulation amplitude, 5-10 G; and multiple scans were used to obtain good signal/noise ratio.

The studies on $\mathrm{Cu}-K$-edge $\mathrm{X}$-ray absorption near-edge structure (XANES) and extended X-ray absorption fine structure (EXAFS) were performed at the National Synchrotron Radiation Research Center (NSRRC) in Hsinchu, Taiwan. The electron storage ring was operated at about $1.5 \mathrm{GeV}$ with a ring current of about $200 \mathrm{~mA}$. These experiments were done at room temperature in transmission mode with ionization detectors. A copper metal foil was placed behind the sample as an on-line energy reference during each scan which usually took about $25 \mathrm{~min}$. The resulting EXAFS data were analyzed using a standard FEFF6 program. A detailed description of the data processing procedures can 
be found in the literature, e.g., Ref. [13]. The data were $k^{3}$-weighted in order to compensate for the attenuation of EXAFS amplitude at high $k$ and then Fourier-transformed over the $k$ range of $2.45-13.5 \mathrm{~A}^{-1}$ with a Hanning apodization function of $d k=2 \mathrm{~A}^{-1}$. Curve fitting of experimental data was done with copper metal as the model compound as in the study of Brown et al. [14].

\subsection{Catalysis}

Catalytic study at $343 \pm 2 \mathrm{~K}$ was done in a three-neck round-bottom flask connected to a water-cooled reflux condenser. A typical mixture contained the following composition, $0.05 \mathrm{~g}$ of catalyst mass; $10 \mathrm{ml}$ of acetonitrile; $3.9 \mathrm{mmol}$ of benzyl alcohol; and $12.4 \mathrm{mmol}$ of TBHP. For product analysis, the reaction mixture was first left standing for 15 min without heating and stirring, and then a portion of the supernatant solution was filtered before analyzed by a Hewlett Packet HP gas chromatograph equipped with a FID and capillary column (Rtx-5, Crossbond 5\% diphenyl-95\% dimethyl polysiloxane, about $30 \mathrm{~m} \times 0.53 \mathrm{~mm}$ i.d.).

Initial activity of the catalyst (after $1 \mathrm{~h}$ of reaction) was expressed in terms of turnover number (TON), which is the number of moles of benzyl alcohol converted per mole of copper per second. Product selectivity is defined as the percentage of each product in the total observed product. These data were based on the elemental carbon analysis. Other minor products are not analyzed.

\section{Results}

\subsection{Chemical analysis}

The amount of phenanthroline in the samples prepared by different methods is listed in Table 1. It can be seen that most of the phenanthroline in the impregnated HPC/MPS sample is lost after washing with $\mathrm{H}_{2} \mathrm{O}$ and the resultant loading is far less than that of the ion-exchanged HPC-M $\mathrm{M}_{\mathrm{T}}$ sample. HPC$\mathrm{M}_{\mathrm{T}}$ has comparable phenanthroline loading to $\mathrm{PN}+\mathrm{CuM}_{\mathrm{T}}$ but is lower than HPC-M . From the content of phenanthroline, we can estimate the amount of HPC complex in some of these samples. For example, $1 \mathrm{~g}$ of the $373 \mathrm{~K}$ dried HPC-M

Table 1

Phenanthroline content of some selected samples

\begin{tabular}{lll}
\hline Sample & Method & Loading $^{\mathrm{a}}\left(\times 10^{-4} \mathrm{~mol} / \mathrm{g}\right)$ \\
\hline $\mathrm{HPC}_{\mathrm{M}} \mathrm{M}^{\mathrm{b}}$ & Impregnation & 2.39 \\
$\mathrm{HPC}_{\mathrm{PS}}$ & Impregnation & 0 \\
$\mathrm{HPC}-\mathrm{M}_{\mathrm{T}}$ & Ion-exchange & 2.89 \\
$\mathrm{HPC}-\mathrm{M}_{\mathrm{P}}$ & Ion-exchange & 4.21 \\
$\mathrm{PN}+\mathrm{CuM}$ & Adsorption & 2.71 \\
$\mathrm{PN}+\mathrm{CuY}$ & Adsorption & 2.68 \\
\hline
\end{tabular}

\footnotetext{
a Calculated from the nitrogen content of the samples.

b Before washing, the rest are washed samples. We found that most of the HPC in this sample can be easily washed away by water.
}

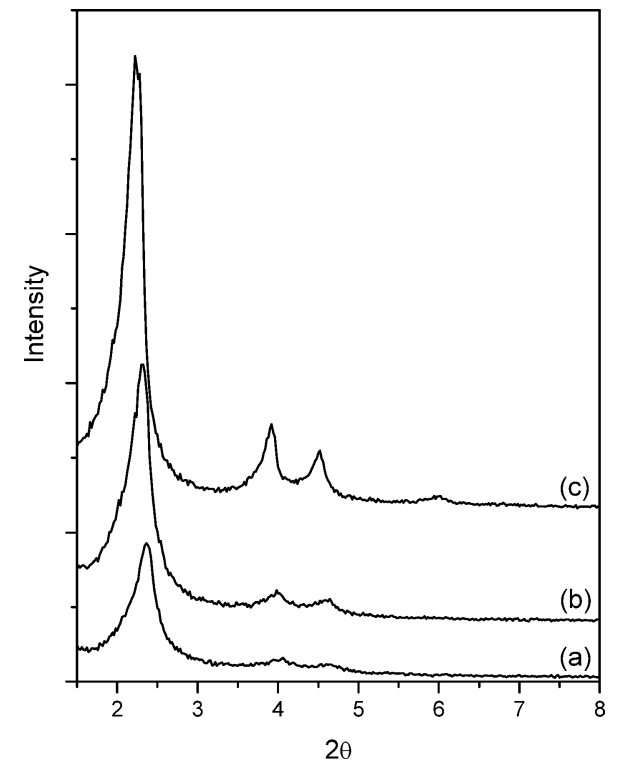

Fig. 1. XRD patterns of (a) PN $+\mathrm{CuM}_{\mathrm{T}}$; (b) $\mathrm{HPC}_{\mathrm{T}}$; and (c) MCM-41.

sample contained about $7.2 \times 10^{-5} \mathrm{~mol}$ of HPC, or equivalent to about $6.3 \mathrm{wt} \%$ of the sample. Similar values of HPC loading can be derived from the TGA profile described in Section 3.3.

We have also analyzed the copper contents of some selected samples and they are $0.77,0.93,1.04$, and $0.87 \mathrm{wt} \%$ for $\mathrm{Cu}-\mathrm{M}_{\mathrm{P}}, \mathrm{HPC}-\mathrm{M}_{\mathrm{T}}, \mathrm{HPC}-\mathrm{M}_{\mathrm{P}}$, and $\mathrm{PN}+\mathrm{CuM}_{\mathrm{T}}$, respectively. From the loading of copper and phenanthroline, the mole ratios of phenanthroline to copper $(\mathrm{PN} / \mathrm{Cu})$ were calculated. They are 2.0, 2.6, and 2.0 for HPC-M $\mathrm{M}_{\mathrm{T}}$, HPC-M $\mathrm{M}_{\mathrm{P}}$, and $\mathrm{PN}+\mathrm{CuM}_{\mathrm{T}}$, respectively. It should be noted that HPC$\mathrm{M}_{\mathrm{P}}$ has a much higher $\mathrm{PN} / \mathrm{Cu}$ value than it would have if its surface species were HPC $(\mathrm{PN} / \mathrm{Cu}=2)$. This would mean that it contains monocupric complexes (e.g., about $60 \%$ of its copper is in the form of $\left.\mathrm{Cu}(\mathrm{PN})_{3}{ }^{2+}\right)$. The mole ratio of copper to aluminum in HPC-M $\mathrm{M}_{\mathrm{T}}$ was also determined and was found to be 0.51 . The amount of aluminum in the sample corresponds to the number of cationic exchange sites.

\subsection{XRD study}

Fig. 1 compares the XRD patterns of $\mathrm{HPC}-\mathrm{M}_{\mathrm{T}}$, PN + $\mathrm{CuM}_{\mathrm{T}}$, and the pristine AlMCM-41 aluminosilicate. Generally, the intensity of the diffraction peaks of AlMCM-41 decreased after the loading of cupric complexes due to the decrease of diffraction contrast. We note that $\mathrm{PN}+\mathrm{CuM}_{\mathrm{T}}$ suffers a greater loss of peak intensities than $\mathrm{HPC}-\mathrm{M}_{\mathrm{T}}$ due probably to the decrease in crystallinity of its MCM- 41 framework.

\subsection{TGA study}

The TGA/DTG profiles of HPC-M $\mathrm{M}_{\mathrm{T}}$ (air-dried) sample are presented in Fig. 2. An air-dried sample was used in this case in order to study the whole process of thermal transformation. The large weight loss below $373 \mathrm{~K}$ is due to 


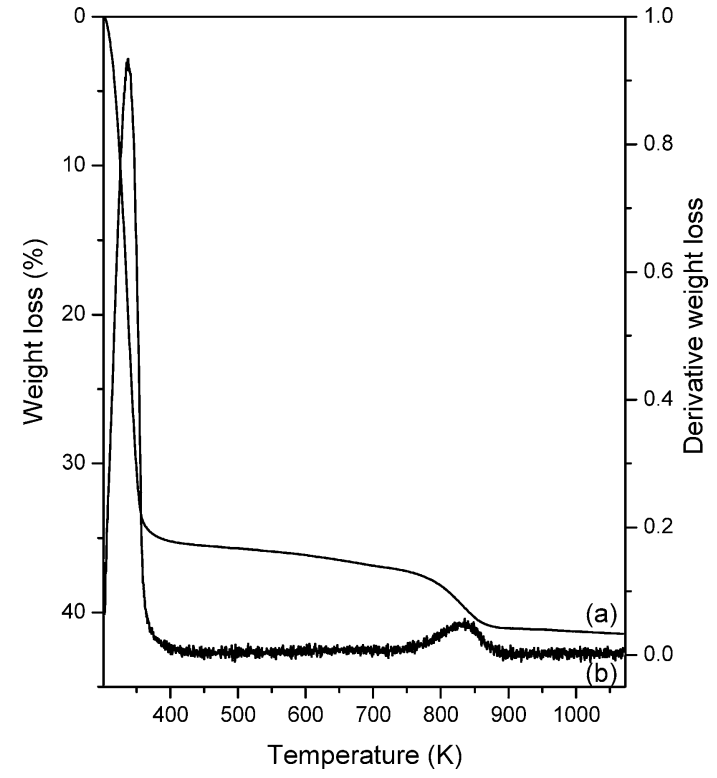

Fig. 2. TGA/DTG profiles of HPC-M $\mathrm{M}_{\mathrm{T}}$ : (a) weight loss; and (b) derivative weight loss.

the desorption of $\mathrm{H}_{2} \mathrm{O}$. Another prominent weight loss occurred at a much higher temperature of $835 \mathrm{~K}$ due to the loss of phenanthroline as HPC decomposed. The corresponding profiles of $\mathrm{PN}+\mathrm{CuM}_{\mathrm{T}}$ (not shown) showed two weight loss stages at 610 and $836 \mathrm{~K}$. The much smaller weight loss seen at lower temperatures can be due to the desorption of free phenanthroline. For HPC/MPS (figure not shown), the weight loss above $373 \mathrm{~K}$ is not distinct but two peaks can still be identified at 572 and $732 \mathrm{~K}$ on the derivative profile corresponding to HPC on the external surfaces and channels of MCM-41, respectively. The latter is less prominent than the former.

\subsection{UV-vis study}

We have measured the UV-vis spectra of $\mathrm{HPC}_{\mathrm{T}} \mathrm{M}_{\mathrm{T}}$, $\mathrm{HPC} / \mathrm{M}_{\mathrm{PS}}, \mathrm{PN}+\mathrm{CuM}_{\mathrm{T}}$, and $\mathrm{PN}+\mathrm{CuY}$ (figures not shown). Two $\mathrm{OH}^{-} \rightarrow \mathrm{Cu}^{2+}$ charge-transfer bands can be seen at 324 and $341 \mathrm{~nm}$ for all samples but they are much less prominent in $\mathrm{PN}+\mathrm{CuY}$. The UV-vis spectra of $\mathrm{HPC}_{-\mathrm{M}}$ and HPC-MP are also compared. The intensity of HPC-M $M_{P}$ in the ligand transition region (below $\sim 300 \mathrm{~nm}$ ) is higher than HPC-M $\mathrm{M}_{\mathrm{T}}$ by about $14 \%$ when the spectra are normalized to the same intensity in the ligand-field transition region of $\mathrm{Cu}^{2+}(>550 \mathrm{~nm})$.

\subsection{EPR study}

Figs. 3A to $\mathrm{C}$ show the EPR spectra recorded at room


spectively. Two spectra for each sample are displayed for different heat treatments. One can see that heat treatment has a very pronounced effect on some of these samples.
In the EPR spectra of PN $+\mathrm{CuY}$ and HPC/MPS, no significant changes in the spectral feature were observed upon heat treatment. For example, the $g_{\perp}$ values in $\mathrm{PN}+\mathrm{CuY}$ are similar, i.e., 2.1010 and 2.0920 for the heating and standing cycles, respectively, and four hyperfine lines due to ${ }^{63} \mathrm{Cu}$ (69\%) and ${ }^{65} \mathrm{Cu}(31 \%)$ both with $I=3 / 2$ are present in both spectra. The hyperfine splitting constants $\left(A_{\|}\right)$are similar to that of HPC-M $\mathrm{M}_{\mathrm{T}}$ after heating. However, we do observe a slight shift in the position of the hyperfine lines in $\mathrm{PN}+\mathrm{CuY}$ due probably to the effect of water.

Conversely, the EPR spectrum of $\mathrm{HPC}_{\mathrm{T}} \mathrm{M}_{\mathrm{T}}$ behaves in a different manner. The spectrum recorded shortly after $373 \mathrm{~K}$ drying in air showed an EPR signal at $g_{\perp}=2.0916$ typical of a monocupric center. It displays a well-resolved four-line hyperfine pattern of the $g_{\|}$component with $A_{\|} \sim 154 \mathrm{G}$. However, when the sample was left standing at room temperature (e.g., a few days), the $g_{\|}$region changed drastically into a broad envelope of hyperfine structures similar to the originally air-dried sample. About seven lines $\left(A_{\|} \sim 74 \mathrm{G}\right)$ can now be resolved from the hyperfine pattern. The $g_{\perp}$ value at 2.0984 , however, is not much different from the previous value. This phenomenon is reversible in the repeated heating/standing cycle. The same phenomenon was also observed in $\mathrm{HPC}-\mathrm{M}_{\mathrm{P}}$ and $\mathrm{PN}+\mathrm{CuM}_{\mathrm{T}}$.

HPC- $\mathrm{M}_{\mathrm{T}}$ and $\mathrm{PN}+\mathrm{CuY}$ also behaved differently as the spectral recording temperature is lowered (Figs. 4A and B). Compared to the spectrum recorded at room temperature, the signal intensity of HPC-M diminished by about two-thirds at $84 \mathrm{~K}$ whereas the signal intensity of $\mathrm{PN}+\mathrm{CuY}$ increased slightly at $90 \mathrm{~K}$. Only HPC-M $\mathrm{M}_{\mathrm{T}}$ gave a slight shift in $g_{\perp}$ value at low temperatures.

In a HPC-M $\mathrm{M}_{\mathrm{T}}$ sample with much higher HPC loading, we observed the $\Delta M_{\mathrm{S}}= \pm 2$ transition at the half-field region $(\sim 1555 \mathrm{G})$ which is the characteristic signal of a triplet state arising from the coupling of two $\mathrm{Cu}^{2+}$ centers (see Fig. 5A). In another experiment, we treated $\mathrm{HPC}-\mathrm{M}_{\mathrm{T}}$ with hydrogen peroxide at room temperature for $1 \mathrm{~h}$, and observed that this signal decreases in intensity as the concentration of hydrogen peroxide is increased (Fig. 5B). Here, the solid was separated from the hydrogen peroxide solution and dried under vacuum before the EPR spectrum was recorded. The new complex formed in this reaction may have very strong coupling between the two $\mathrm{Cu}^{2+}$ ions in the dicupric center, or the dicupric center is being destroyed.

\section{6. $C u$-K-edge XANES and EXAFS studies}

The XANES spectra and their derivative of HPC- $\mathrm{M}_{\mathrm{T}}$ and $\mathrm{PN}+\mathrm{CuY}$ are compared in Fig. 6 . The spectra of both samples showed a small preedge peak ( $1 \mathrm{~s} \rightarrow 3 \mathrm{~d}$ transition) at $8976.2 \mathrm{eV}$ but their edge structures are quite different. It is evident from the derivative curves that the absorption edge energy of $\mathrm{HPC}-\mathrm{M}_{\mathrm{T}}$ (and also HPC-M and $\mathrm{PN}+\mathrm{CuM}_{\mathrm{T}}$ ) is slightly higher than $\mathrm{PN}+\mathrm{CuY}$ (and also $\mathrm{Cu}-\mathrm{Y}$ ). For example, the energy of $1 \mathrm{~s} \rightarrow 4 \mathrm{~s}$ transition in the former (maximum at $8987.4 \mathrm{eV}$ ) is at least $0.8 \mathrm{eV}$ higher than the latter 


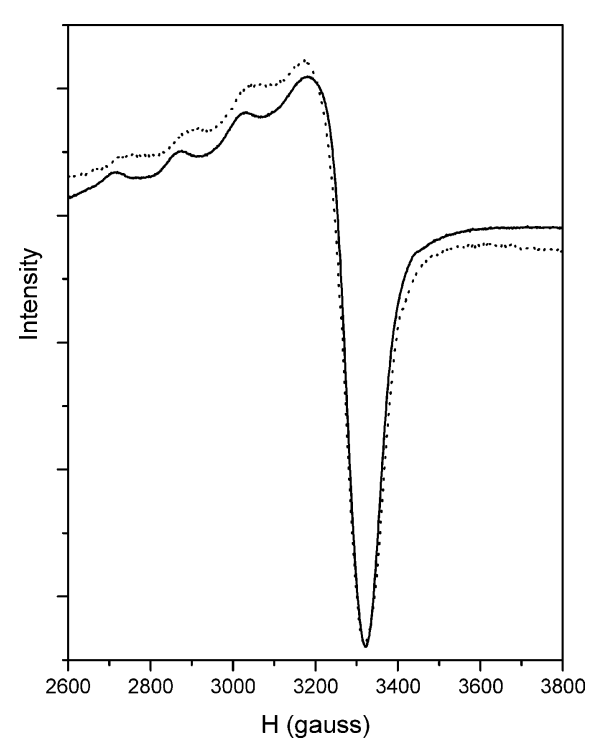

(A)

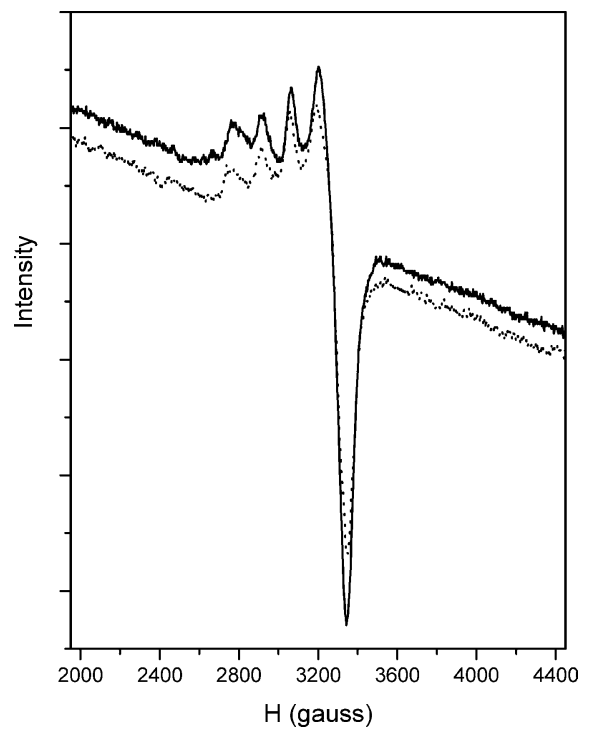

(B)

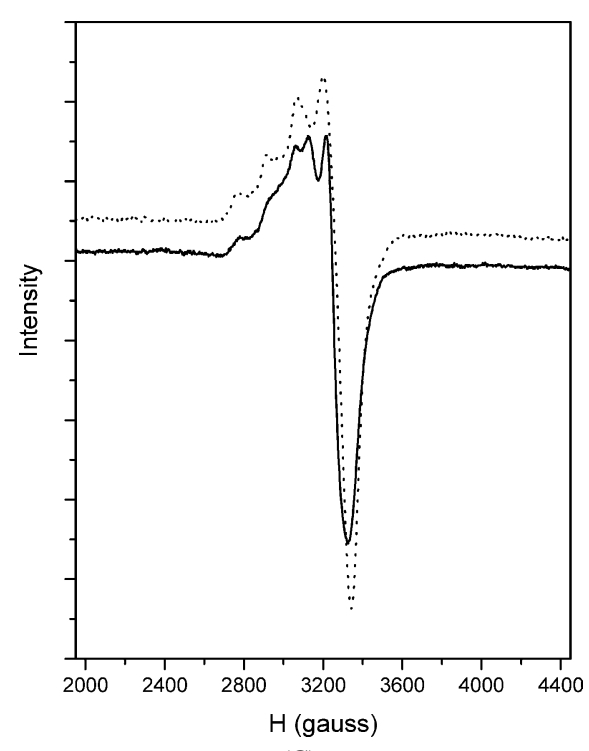

(C)

Fig. 3. EPR spectra of (A) PN + CuY, (B) HPC/M $\mathrm{M}_{\mathrm{PS}}$, and (C) HPC-M $\mathrm{M}_{\mathrm{T}}$, showing the effect of heat treatment: after drying at $373 \mathrm{~K}$ (dotted line); and after standing at room temperature for a few days (solid line). The spectra were taken at room temperature.

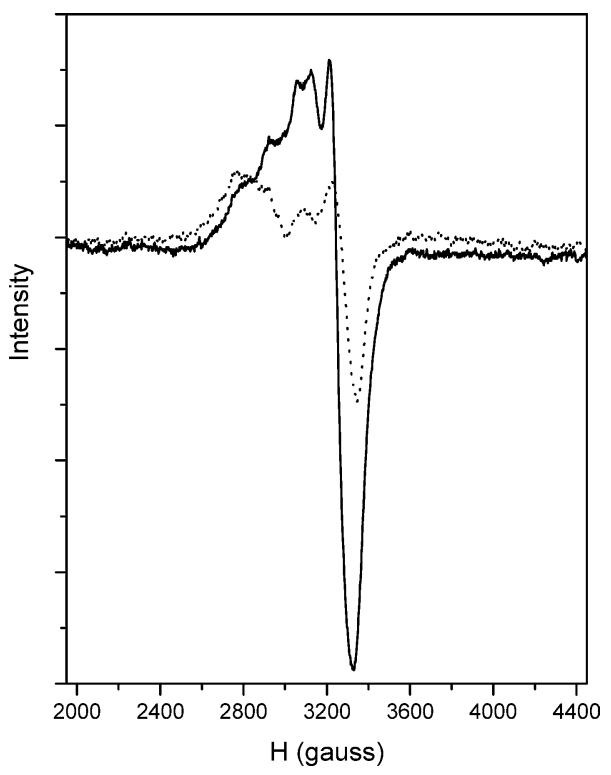

(A)

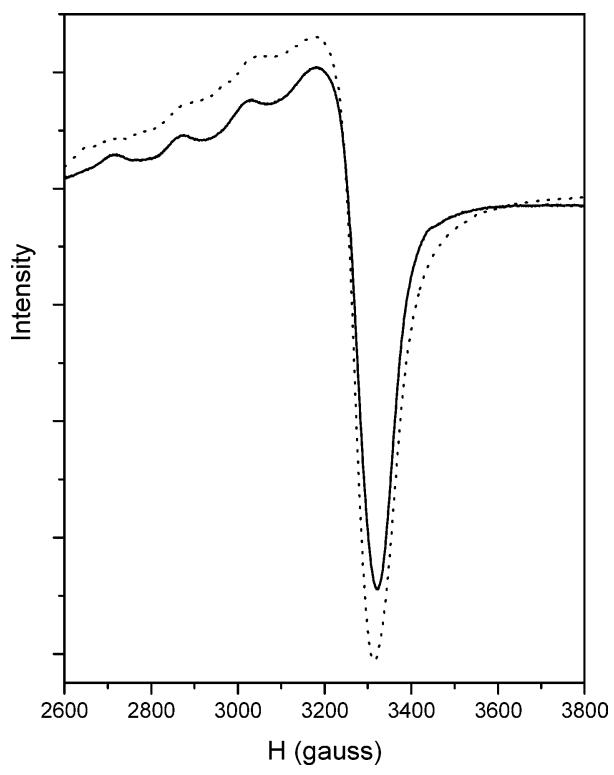

(B)

Fig. 4. (A) EPR spectra of HPC-M $\mathrm{M}_{\mathrm{T}}$ at different recording temperatures: room temperature (solid line); and $84 \mathrm{~K}$ (dotted line). (B) EPR spectra of PN $+\mathrm{CuY}$ at different recording temperatures: room temperature (solid line); and $90 \mathrm{~K}$ (dotted line).

(maximum at $8986.6 \mathrm{eV}$ ). The transition energy of the HPC$\mathrm{M}_{\mathrm{T}}$ sample is also quite inhomogeneously distributed.

Fig. 7 compares the EXAFS spectra (not corrected for phase shift) of the following samples: (a) pure HPC, (b) $\mathrm{PN}+\mathrm{CuM}_{\mathrm{T}}$, (c) HPC/MPS, (d) HPC-MP, (e) HPC-M and (f) $\mathrm{PN}+\mathrm{CuY}$. The peaks in the spectra correspond to various scattering or neighboring atom(s) situated at different distances from the central absorbing copper atom. The assignment of the peaks is indicated in the figure. Here, N/O represents both nitrogen and oxygen scatterers. The assignment of the $\mathrm{Cl}$ peak is made with reference to the $\mathrm{Cu}-\mathrm{Cl}$ bond distance reported in the literature [15]. Accordingly, it is not significant in the samples prepared by adsorption techniques. The identity of the Al peak is confirmed by a comparison with the EXAFS spectrum of $\mathrm{Cu}-\mathrm{Y}$ (not shown). The notation "Al" is used loosely here to denote surface aluminum or silicon atoms of the support. Also, by comparing the spectra of $\mathrm{PN}+\mathrm{CuY}$ and $\mathrm{Cu}-\mathrm{Y}$, we note that the shoul- 


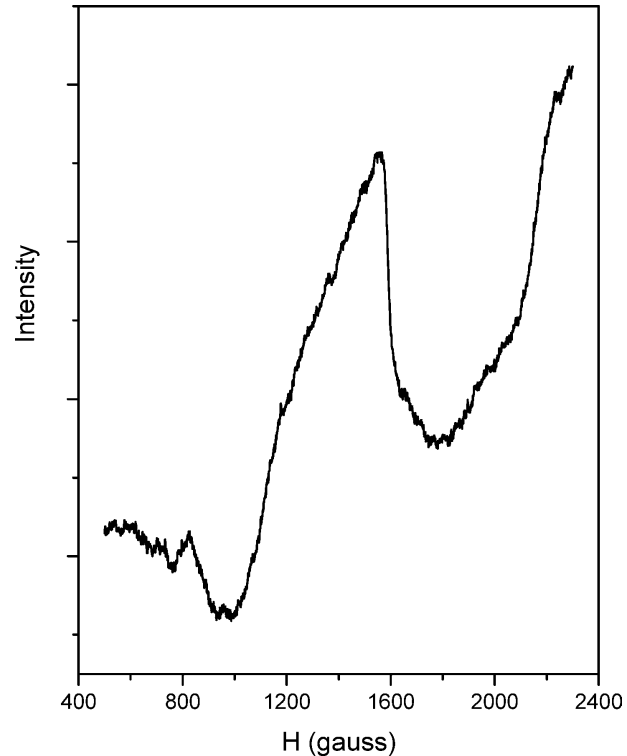

(A)

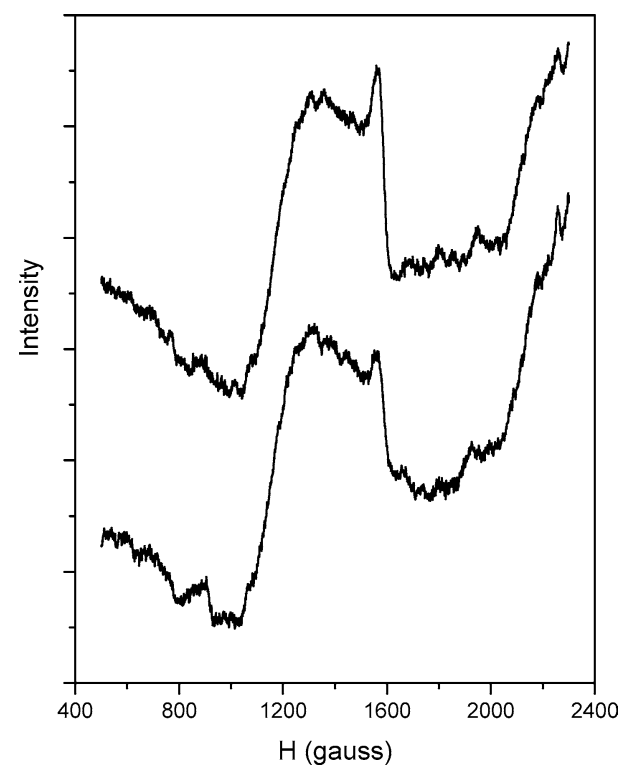

(B)

Fig. 5. (A) EPR spectrum of the triplet state half-field transition $\left(\Delta M_{\mathrm{S}}= \pm 2\right)$ for HPC-M $\mathrm{M}_{\mathrm{T}}$ with a higher loading of HPC and recorded at $84 \mathrm{~K}$. (B) EPR spectra of HPC-M after reaction with hydrogen peroxide and recorded at $84 \mathrm{~K}$ : $0.05 \mathrm{~g}$ of sample in $10 \mathrm{ml}$ of $0.1 \mathrm{M} \mathrm{H}_{2} \mathrm{O}_{2}$ solution (top); and $0.5 \mathrm{M} \mathrm{H}_{2} \mathrm{O}_{2}$ solution (bottom).

der of this peak is largely contributed by the phenanthroline ligand. Most importantly, two $\mathrm{Cu}$ peaks are prominent in $\mathrm{HPC}_{\mathrm{T}}, \mathrm{M}_{\mathrm{T}}, \mathrm{HPC}-\mathrm{M}_{\mathrm{P}}, \mathrm{HPC} / \mathrm{M}_{\mathrm{PS}}$, and $\mathrm{PN}+\mathrm{CuM}_{\mathrm{T}}$ but not $\mathrm{PN}+\mathrm{CuY}$, as expected. The basis of their assignment will be discussed separately in Section 4.3.

For comparison purposes, we have also taken the EXAFS spectrum of a pure HPC complex. Two $\mathrm{Cu}$ peaks are also observed but the first $\mathrm{Cu}$ peak is relatively small. This may be due to perturbation of the molecule under intense X-ray absorption. Considerable attention should be focused on the difference of EXAFS spectral feature between $\mathrm{HPC}_{\mathrm{T}} \mathrm{M}_{\mathrm{T}}$ and
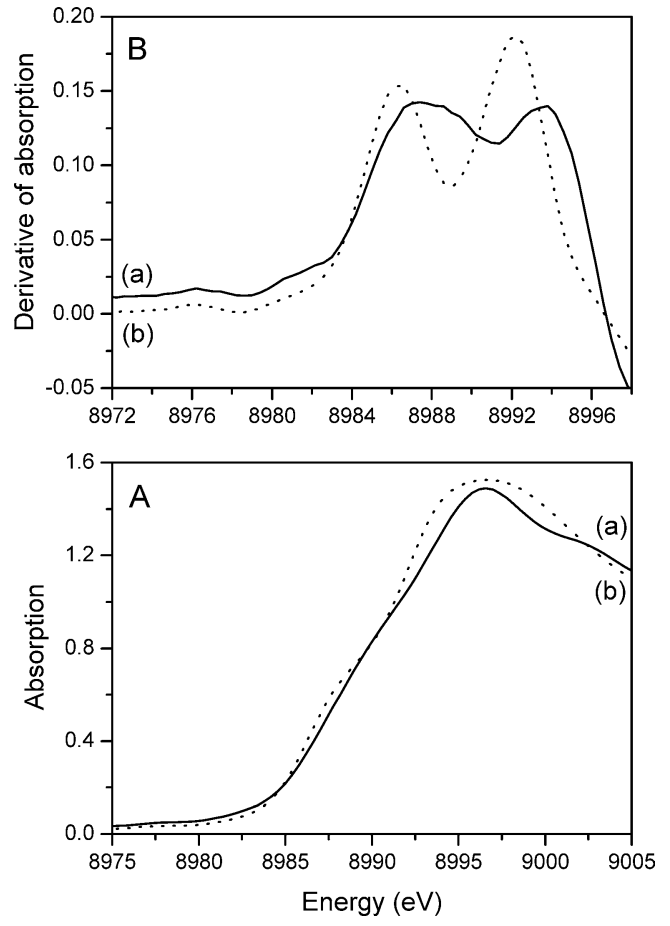

Fig. 6. $\mathrm{Cu}-K$-edge XANES original (A) and derivative (B) spectra of (a) $\mathrm{HPC}_{\mathrm{T}}$; and (b) PN $+\mathrm{CuY}$

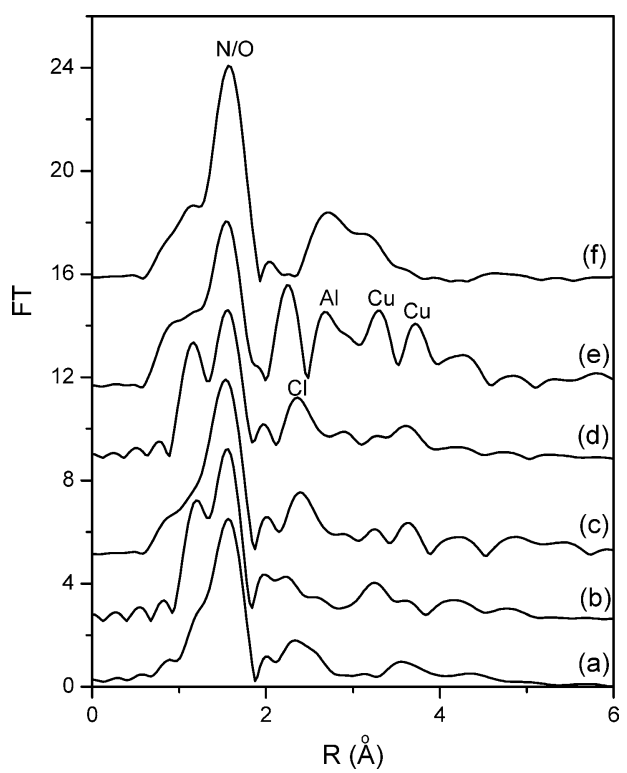

Fig. 7. Cu-K-edge EXAFS spectra of (a) pure $\mathrm{HPC}$; (b) $\mathrm{PN}+\mathrm{CuM}_{\mathrm{T}}$; (c) $\mathrm{HPC}_{\mathrm{MS}}$; (d) HPC-MP; (e) HPC-M ; and (f) PN + CuY.

HPC-MP. It can be seen that the intensity of $\mathrm{Cu}$ peaks is much lower in HPC-M than HPC-M $\mathrm{M}_{\mathrm{T}}$. The Al peak is also not significant in $\mathrm{HPC}-\mathrm{M}_{\mathrm{P}}$, and the $\mathrm{Cu}-\mathrm{Cl}$ distance shifted slightly to a longer distance as in the case of HPC/MPS. This observation is in line with the conclusion drawn from chemical analysis that a monocupric complex is present in HPC-M $\mathrm{M}_{\mathrm{P}}$. The presence of a monocupric complex causes a decrease in the average coordination number of the copper 


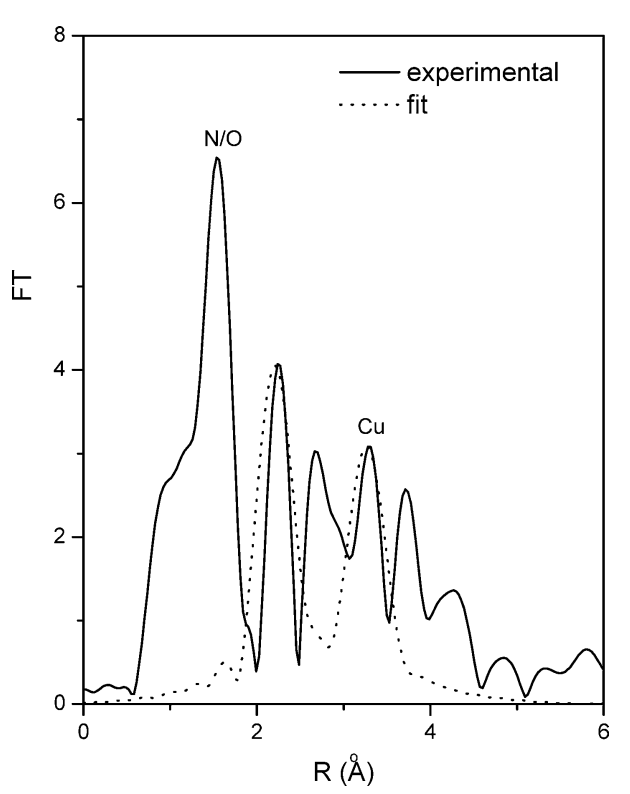

Fig. 8. Theoretical fitting of Fig. 7e with the following parameters: $\Delta r=-0.0746 \AA, \Delta \sigma^{2}=0$, and $\Delta E_{\mathrm{o}}=7.2240 \mathrm{eV}$.

center due to copper scatterers and this effect is revealed in the intensity of the $\mathrm{Cu}$ peaks.

A theoretical fitting of the first $\mathrm{Cu}$ peak for $\mathrm{HPC}-\mathrm{M}_{\mathrm{T}}$ is given in Fig. 8. The coordination number $(N)$ and bond distance $(R)$ of copper scatterer can be evaluated by curvefitting techniques. The first $\mathrm{Cu}$ peak in $\mathrm{HPC}-\mathrm{M}_{\mathrm{T}}$ can be fitted quite nicely except a slight discrepancy in amplitude. $R$ and $N$ values were estimated as $3.54 \AA$ and 0.68 , respectively. The fitting parameters are $\Delta r=-0.0746 \AA, \Delta \sigma^{2}=0$, and $\Delta E_{\mathrm{o}}=7.2240 \mathrm{eV}$ which are the shifts in the bond distance, Debye-Waller factor, and edge energy, respectively.

The Fourier-filtered EXAFS spectra of N/O, first $\mathrm{Cu}$, and second $\mathrm{Cu}$ peaks in $\mathrm{HPC}-\mathrm{M}_{\mathrm{T}}$ are presented in Figs. 9A, B, and $\mathrm{C}$, respectively. In the case of N/O peak, the amplitude function shows a decreasing amplitude of the EXAFS oscillation at higher wave vectors and the maximum is found at $k \approx 4.1 \AA^{-1}$. However, the trend is reversed in the amplitude functions of the first and second peaks of $\mathrm{Cu}$ scatterer with maxima at $k \approx 10.7$ and $11.7 \AA^{-1}$, respectively. The dotted line profile also showed the fitting of HPC-M $\mathrm{M}_{\mathrm{T}}$ as reported in Fig. 8.

We have also found that the supported HPC decomposed during the data collection process and the original blue color of the sample turned dark. Accordingly, most of the peaks of HPC-M $\mathrm{M}_{\mathrm{T}}$ in Fig. 7 decreased in intensity after the sample was subjected to a repeated scan. In addition, the relative intensity of the first and second $\mathrm{Cu}$ peaks is now reversed; i.e., the second $\mathrm{Cu}$ peak is now slightly more intense than the first.

\subsection{Catalytic study}

Table 2 compares the catalytic performance of $\mathrm{HPC}-\mathrm{M}_{\mathrm{T}}$, $\mathrm{HPC}_{\mathrm{P}} \mathrm{M}_{\mathrm{P}}$, and $\mathrm{Cu}-\mathrm{M}_{\mathrm{P}}$ in benzyl alcohol oxidation reaction
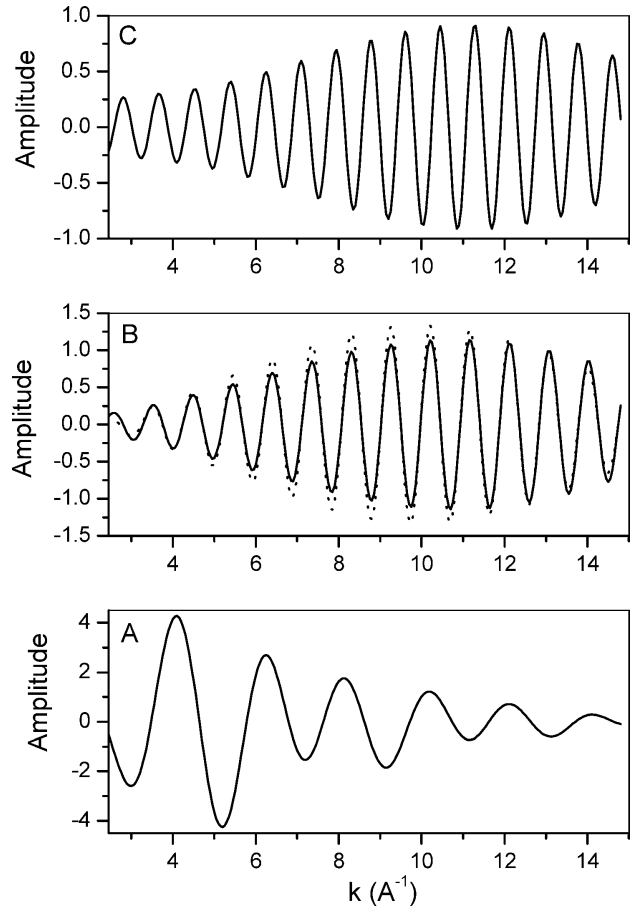

Fig. 9. Fourier-filtered spectra of $\mathrm{HPC}_{\mathrm{T}} \mathrm{M}_{\mathrm{T}}$ : (A) N/O peak; (B) first Cu peak; and $(\mathrm{C})$ second $\mathrm{Cu}$ peak. The dotted line represents the fitting curve.

Table 2

Catalytic activity of benzyl alcohol oxidation reaction at $343 \mathrm{~K}$

\begin{tabular}{llll}
\hline Catalyst & TON $^{\mathrm{a}}\left(\mathrm{s}^{-1}\right)$ & Selectivity $^{\mathrm{a}}(\%)$ & \\
\cline { 3 - 4 } & & Benzaldehyde & Benzoic acid \\
\hline $\mathrm{Cu}-\mathrm{M}_{\mathrm{P}}$ & $2.1 \times 10^{-2}$ & 91 & 9 \\
$\mathrm{HPC}-\mathrm{M}_{\mathrm{P}}$ & $0.1 \times 10^{-2}$ & 100 & 0 \\
$\mathrm{HPC}_{\mathrm{M}}$ & $2.0 \times 10^{-2}$ & 100 & 0 \\
\hline
\end{tabular}

a Calculated from catalytic data taken after $1 \mathrm{~h}$ of reaction.

with TBHP at $343 \mathrm{~K}$. We can see that the initial activity of $\mathrm{HPC}_{\mathrm{T}} \mathrm{M}_{\mathrm{T}}$ is comparable to $\mathrm{Cu}-\mathrm{M}_{\mathrm{P}}$ while $\mathrm{HPC}-\mathrm{M}_{\mathrm{P}}$ is much less active. However, if we look at the reactivity of the active center, then the dicupric center of $\mathrm{HPC}-\mathrm{M}_{\mathrm{T}}$ is about twice that of the monocupric center of $\mathrm{Cu}-\mathrm{M}_{\mathrm{P}}$. A larger amount of benzoic acid was produced in $\mathrm{Cu}-\mathrm{M}_{\mathrm{P}}$ relative to $\mathrm{HPC}$ $\mathrm{M}_{\mathrm{T}}$ and HPC-M . We have also noted that the clear reaction solution in the case of $\mathrm{Cu}-\mathrm{M}_{\mathrm{P}}$ turned light brown in less than $1 \mathrm{~h}$, and the catalyst lost its original light blue color. These changes are not observed for $\mathrm{HPC}_{\mathrm{T}} \mathrm{M}_{\mathrm{T}}$ and $\mathrm{HPC}-\mathrm{M}_{\mathrm{P}}$.

\section{Discussion}

\subsection{Overview}

The search for artificial enzymes has always been the topic of dynamic and continuing research and it has been the subject of several reviews $[1,6,16]$. Our interest in employing HPC as the precursor for the enzyme hemocyanin was prompted by its open structure in the inert state and 
easy activation as a reactant molecule in a bridged dicopper complexes [17]. We took a possible route to immobilize its precursor onto a backbone support and then generate the active hemocyanin state in situ during a catalytic reaction.

Ion exchange is a simple and one-step ion-exchange method to introduce HPC into the channel structure of MCM-41 without the need for crystallizing HPC. In the synthesis medium, HPC is formed according to the equilibrium reaction:

$2 \mathrm{Cu}^{2+}+4 \mathrm{PN}+\mathrm{H}_{2} \mathrm{O} \leftrightarrow\left[(\mathrm{PN})_{2} \mathrm{Cu}(\mathrm{OH}) \mathrm{Cu}(\mathrm{PN})_{2}\right]^{3+}+\mathrm{H}^{+}$.

Here, $\mathrm{M}_{\mathrm{T}}$ or $\mathrm{M}_{\mathrm{P}}$ was added directly to the synthesis medium and they act both as base and ion exchanger, thereby shifting the equilibrium toward the direction of HPC. However, the degree of ion exchange is not determined since it depends on the net charge of HPC which can vary from +1 to +3 . The net charge on each HPC depends on the number of $\mathrm{Cl}^{-}$ which is not determined.

As shown in the results of chemical analysis and TGA study, the phenanthroline loading which approximates the amount of cupric complex is much lower in HPC/MPS than $\mathrm{HPC}_{\mathrm{T}} \mathrm{M}_{\mathrm{T}}, \mathrm{HPC}-\mathrm{M}_{\mathrm{P}}$, and PN $+\mathrm{CuM}_{\mathrm{T}}$. Therefore, the anionic surface of aluminum-substituted AlMCM-41 can retain much more HPC cations after washing than the neutral surface of pure silica MCM-41. As expected, the $\mathrm{PN} / \mathrm{Cu}$ value for $\mathrm{HPC}-\mathrm{M}_{\mathrm{T}}$ is 2 . The surprisingly high $\mathrm{PN} / \mathrm{Cu}$ value for HPC-MP seems to indicate the presence of monocupric complexes such as $\mathrm{Cu}(\mathrm{PN})_{3}{ }^{2+}$. A similar conclusion can be drawn from EXAFS study. As free phenanthroline ligand is deposited on the surface of $\mathrm{PN}+\mathrm{CuM}_{\mathrm{T}}$, the average number of phenanthroline coordinated to copper should be less than the observed $\mathrm{PN} / \mathrm{Cu}$ value of 2 ; i.e., some $\mathrm{Cu}(\mathrm{PN})_{x}{ }^{2+}$ $(x<2)$ is also present.

\subsection{Metal-ligand interaction}

The interaction between copper center and ligand was revealed by XANES study. The $\mathrm{Cu}-K$-edge $1 \mathrm{~s} \rightarrow 4$ s transition energies of $\mathrm{Cu}-\mathrm{Y}$ and $\mathrm{PN}+\mathrm{CuY}$ are consistent with literature data of cupric ions [14]. It is not surprising that the neutral phenanthroline ligand does not affect this transition energy in $\mathrm{PN}+\mathrm{CuY}$. On the other hand, one observed that the $\mathrm{Cu}-K$-edge $1 \mathrm{~s} \rightarrow 4 \mathrm{~s}$ transition energy of $\mathrm{HPC}_{\mathrm{T}} \mathrm{M}_{\mathrm{T}}$, HPC$\mathrm{M}_{\mathrm{P}}$, and $\mathrm{PN}+\mathrm{CuM}_{\mathrm{T}}$ shifted toward higher energy relative to $\mathrm{PN}+\mathrm{CuY}$ and $\mathrm{Cu}-\mathrm{Y}$. This observation strongly supports the presence of HPC in $\mathrm{HPC}_{\mathrm{T}}, \mathrm{M}_{\mathrm{T}}, \mathrm{HPC}-\mathrm{M}_{\mathrm{P}}$, and PN $+\mathrm{CuM}_{\mathrm{T}}$ where a bridging ligand between the two $\mathrm{Cu}^{2+}$ centers allows the unpaired electron to delocalize between them. The presence of a hydroxo bridge in HPC of these samples is also indicated by the $\mathrm{OH}^{-} \rightarrow \mathrm{Cu}^{2+}$ charge-transfer bands normally occurring between 300 and $400 \mathrm{~nm}[18,19]$. However, the relative concentration of HPC in these samples varies.

\subsection{Dicupric center of $H P C$}

The radial distribution function (RDF) of a copper center can be determined with a $\mathrm{Cu}-K$-edge EXAFS technique. Each peak in the EXAFS spectrum corresponds to a coordinating shell of scatterer(s) situated at a given distance from the central copper atom. The assignment of nitrogen/oxygen $(\mathrm{N} / \mathrm{O})$ and $\mathrm{Cu}$ peaks is confirmed by their Fourier-filtered profiles. The trends of decreasing amplitude for the former and increasing amplitude for the latter in the EXAFS oscillations at higher $k$ are consistent with the reported results $[14,20]$. Also, their profiles for nitrogen and copper scatterers maximizing at $k \sim 5$ and 10 , respectively, are consistent with our results. From our EXAFS results, five major points can be inferred.

\subsubsection{Two $\mathrm{Cu}$ to $\mathrm{Cu}$ distances in $\mathrm{HPC}-\mathrm{M}_{T}$}

The structure of HPC complex remained intact in the mesopores of AlMCM-41 ( $27 \AA)$. The presence of dicupric center is clearly shown by the $\mathrm{Cu}$ to $\mathrm{Cu}$ distances. It sits close to the negatively charged surface exchanged site of $\mathrm{M}_{\mathrm{T}}$, as revealed by the $\mathrm{Cu}$ to $\mathrm{Al}$ or $\mathrm{Si}$ distance. Both oxygen (either from hydroxo bridge or water) and nitrogen (from phenanthroline) scatterers appear at similar bond distances $(\sim 2 \AA)$ and therefore their peaks in the RDF profiles cannot be resolved. Here, $\mathrm{Cl}^{-}$acts as a charge balancing anion. We propose the following structural formula to represent HPC$\mathrm{M}_{\mathrm{T}}$ substrate:

\section{$\left[\mathrm{M}_{\mathrm{T}}\right]^{-}\left[\mathrm{Cl}(\mathrm{PN})_{2} \mathrm{Cu}(\mathrm{OH}) \mathrm{Cu}(\mathrm{PN})_{2} \mathrm{Cl}\left(\mathrm{H}_{2} \mathrm{O}\right)\right]^{+}$.}

It is interesting to note that there are two $\mathrm{Cu}$ peaks assignable to two $\mathrm{Cu}$ to $\mathrm{Cu}$ distances (Fig. 7e). The shorter $\mathrm{Cu}$ to $\mathrm{Cu}$ distance (first $\mathrm{Cu}$ peak) belongs to the pristine HPC complex with a bond distance of $3.54 \AA$, which is quite close to the reported value for hemocyanin $(3.67 \AA)$ [14]. It can be assigned to a $\mathrm{Cu}-\mathrm{O}-\mathrm{Cu}$ distance. It is reasonable to find that its estimated coordination number of 0.68 is less than the idealized value of 1 since partial dissociation (and also decomposition) of the complex occurred when the sample was subjected to X-ray irradiation during the EXAFS experiments. This phenomenon also explains the appearance of a new $\mathrm{Cu}$ to $\mathrm{Cu}$ distance (second $\mathrm{Cu}$ peak) at about $0.43 \AA$ longer than the original one. In other words, this is the intermediate stage during the transformation of HPC to monocupric complexes upon irradiation by X-ray. Thus, it can be assigned to a $\mathrm{Cu}-\mathrm{Cu}$ distance. After prolong irradiation by $\mathrm{X}$-ray, the relative intensity of this $\mathrm{Cu}-\mathrm{Cu}$ peak is greater than that of the $\mathrm{Cu}-\mathrm{O}-\mathrm{Cu}$ peak and thus further supports the identity of this intermediate species. Similarly, the $\mathrm{Cu}-\mathrm{O}-\mathrm{Cu}$ peak in a pure HPC complex is very small compared to the $\mathrm{Cu}-\mathrm{Cu}$ peak and this is probably due to the absence of the stabilization effect of the support when the sample is subjected to $\mathrm{X}$-ray irradiation.

\subsubsection{Structure of $P N+C u Y$}

We did not observe dicupric centers as no $\mathrm{Cu}$ to $\mathrm{Cu}$ bond distance can be assigned in the micropores of zeolite $\mathrm{Y}$ 
$(\sim 13 \AA)$. This result shows unambiguously that a dicupric complex is formed in MCM-41 while a monocupric complex is formed in Y zeolite.

\subsubsection{Structure of $H P C / M_{P S}$}

The residual amount of HPC remained both in the channels and on the external surfaces of MCM-41 after the washing process. Based on the results of TGA study, a larger fraction of HPC is adsorbed on the external surface of MCM41 and they are dissociated irreversibly after drying at $373 \mathrm{~K}$ since there is no surface charge and confined space to hold the dicupric center in place (see Section 4.5).

\subsubsection{Structure of $P N+C u M_{T}$}

One observed that dicupric complexes similar to HPC can also be made via this two-step process. Here, the channel of MCM-41 acts as a nanoscale reactor for the synthesis of dicupric complexes from copper salt, phenanthroline ligand, and water [see Eq. (1)]. However, the concentration of this complex in the mesopores of MCM-41 may not be as high as in $\mathrm{HPC}-\mathrm{M}_{\mathrm{T}}$. In addition, the cupric species in $\mathrm{PN}+\mathrm{CuM}_{\mathrm{T}}$ are disorderly oriented in the channels judging from the diminishing Al peak intensity in the EXAFS spectrum.

\subsubsection{Morphological effect of MCM-41}

We observed that more HPC can be introduced into the tubular sample than the particulate sample due to the large amount of structural defect in the former. These defects help the diffusion of bulky HPC in tubular MCM-41 by interconnecting the unidimensional channel system originally present as in the case of particulate AlMCM-41 [21]. Diffusion of HPC in the unidimensional channels of particulate AlMCM-41 sample is more susceptible to blocking compared to monocupric species and this explains the exceptionally high $\mathrm{PN} / \mathrm{Cu}$ value and low intensity of $\mathrm{Cu}$ peaks in the EXAFS spectrum of HPC-M relative to HPC-M $\mathrm{M}_{\mathrm{T}}$. In addition, this morphological effect of MCM-41 also explains the higher intensity of UV-vis absorption bands in the ligand transition region of HPC-M compared to HPC- $\mathrm{M}_{\mathrm{T}}$, since a higher $\mathrm{PN} / \mathrm{Cu}$ value is found for the former.

\subsection{Superexchange interaction}

HPC possesses a pair of $\mathrm{Cu}^{2+}$ ions and they will stay close to each other due to the action of the hydroxo bridge. Electron exchange coupling between the two unpaired electrons (holes) of the dicupric center can occur through the intervening hydroxide ion $[22,23]$. When the superexchange is weak, the EPR spectrum is analogous to that expected for a combination of two independent doublet states. For fast superexchange (e.g., strong antiferromagnetically coupled $S=1 / 2$ system), the ground state of the dicupric center is a singlet and the triplet state can be thermally populated.

The results of our EPR study provide strong confirmation of the presence of a bridge between the dicupric center in $\mathrm{HPC}_{\mathrm{M}} \mathrm{M}_{\mathrm{T}}$. First, the number of hyperfine lines is more than four $\left(I=3 / 2\right.$ for ${ }^{63} \mathrm{Cu}$ and $\left.{ }^{65} \mathrm{Cu}\right)$ and this indicates strong coupling between the two unpaired electrons on the dicupric center. The broadening of the hyperfine structure in the $g_{\|}$ region indicates that the two $\mathrm{Cu}^{2+}$ ions are $\leqslant 5 \AA$ apart [24]. This finding is consistent with the $\mathrm{Cu}-\mathrm{O}-\mathrm{Cu}$ distance observed by EXAFS techniques. A monocupric complex such as the one in $\mathrm{PN}+\mathrm{CuY}$ has only four hyperfine lines of larger $A_{\|}$value since the electron is now localized on a single $\mathrm{Cu}^{2+}$ ion. Secondly, the signal intensity of HPC-M decreased at low recording temperatures. This is due to the thermal depopulation of the triplet state into singlet state. This observation is consistent with the magnetic study of Haddad et al. [10] on bulk HPC. Thirdly, the $g_{\perp}$ value of 2.0984 is also consistent with the triplet state $\Delta M_{\mathrm{S}}= \pm 1$ transition of known monohydroxo-bridged dicupric complexes [25]. Finally, the triplet state $\Delta M_{\mathrm{S}}= \pm 2$ transition is observed at the half-field region of $\Delta M_{\mathrm{S}}= \pm 1$ transitions.

In the case of HPC-MP and PN $+\mathrm{CuM}_{\mathrm{T}}$, broadening of hyperfine structures in the $g_{\|}$region is also observed, indicating the possible presence of dicupric complexes. However, they are not studied in details.

\subsection{Reversibility of bridging ligand}

The reversible transformation of the dicupric center in HPC-M $\mathrm{M}_{\mathrm{T}}, \mathrm{HPC}-\mathrm{M}_{\mathrm{P}}$, and $\mathrm{PN}+\mathrm{CuM}_{\mathrm{T}}$ to monocupric center after drying at $373 \mathrm{~K}$ also revealed the presence of a hydroxo bridge between the two $\mathrm{Cu}^{2+}$ centers. This reversible transformation probably proceeds according to the equilibrium reaction outlined in

$\left[(\mathrm{PN})_{2} \mathrm{Cu}(\mathrm{OH}) \mathrm{Cu}(\mathrm{PN})_{2}\right]^{3+}+\mathrm{H}^{+} \leftrightarrow 2(\mathrm{PN})_{2} \mathrm{Cu}^{2+}+\mathrm{H}_{2} \mathrm{O}$.

From our EPR results ( $g_{\|} \sim 2.2760$ and $A_{\|} \sim 154 \mathrm{G}$ ), the intermediate state of HPC decomposition is probably a square planar complex whereby the $\mathrm{Cu}^{2+}$ center is coordinated by four nitrogen atoms [26]. During the exchange reaction [see Eq. (1)], some protons will migrate into AlMCM-41 as well. When the surface water, which poisons the acid sites, is removed by heating, interaction between the hydroxo ligand and the surrounding protons may occur and this will lead to the dissociation of HPC. We have also shown in the preparation of $\mathrm{PN}+\mathrm{CuM}_{\mathrm{T}}$ that a bridge can be added to two isolated $\mathrm{Cu}^{2+}$ centers in MCM-41 channels. This finding further support the possibility of the reversible reaction noted above.

The reversibility of bridging ligand leads us to speculate the possibility of replacing the hydroxo-bridging ligand of HPC- $\mathrm{M}_{\mathrm{T}}$ with hydroperoxo ligand by the reaction with hydrogen peroxide or TBHP. Indeed, the "EPR silent" complex formed during this reaction (Fig. 5B) can be assigned to the hydroperoxo-bridged dicupric-phenanthroline complex, or its decomposition products. A similar study with other hydroxo complexes has also been reported [20]. We may draw an analogy between the reaction pathways of $\mathrm{HPC}-\mathrm{M}_{\mathrm{T}}$ with 
peroxides and those of oxyhemocyanin, where the peroxo bridge is just a deprotonated form of hydroperoxo species.

\subsection{Catalytic behavior}

We carried out a simple catalytic study to characterize our catalysts. We chose the oxidation of benzyl alcohol by TBHP which is a facile reaction with simple product distribution. We use smaller reactant molecules and catalysts with low copper loading so that the diffusional constraint of molecules in the MCM- 41 channels is minimum. In addition, only initial rates are compared so that complication due to coking and secondary reactions is minimized. The main goal of this catalytic study is to ascertain the role of the hydroxobridging ligand of HPC in the oxidation reaction.

The performance of HPC-M $\mathrm{M}_{\mathrm{T}}$ and HPC-M $\mathrm{M}_{\mathrm{P}}$ in the oxidation of benzyl alcohol was tested and compared with the reference $\mathrm{Cu}-\mathrm{M}_{\mathrm{P}}$ catalyst. It is not surprising that $\mathrm{Cu}-\mathrm{M}_{\mathrm{P}}$ has high reactivity since each $\mathrm{Cu}^{2+}$ is involved in the reaction and has no coordinating ligands affecting the formation of reactive intermediates. We observed that the initial rate of reaction of $\mathrm{HPC}-\mathrm{M}_{\mathrm{T}}$ is comparable to $\mathrm{Cu}-\mathrm{M}_{\mathrm{P}}$. However, in terms of the reactivity per active site, this would mean that the conversion of benzyl alcohol on the dicupric site of HPC-M $\mathrm{M}_{\mathrm{T}}$ is twice faster than that on the monocupric site of $\mathrm{Cu}-\mathrm{M}_{\mathrm{P}}$. After $6 \mathrm{~h}$ of reaction at $343 \mathrm{~K}$, about $12 \%$ of the total amount of copper in HPC-M $\mathrm{M}_{\mathrm{T}}$ is leached into the solution medium. It could not be reused since the organic ligands would be destroyed during the catalyst regeneration process by heating in air at high temperatures.

The initial rate of benzyl alcohol oxidation on HPC-M $\mathrm{M}_{\mathrm{P}}$ is much lower. As we have suggested that the cupric complexes in $\mathrm{HPC}-\mathrm{M}_{\mathrm{P}}$ is about $60 \% \mathrm{Cu}(\mathrm{PN})_{3}{ }^{2+}$, it is likely that this monocupric complex does not contribute significantly to the rate of reaction since its cupric center is completely shielded by the phenanthroline ligands. Besides, the monocupric complexes can also slow down the diffusion rate of the reactant to the active HPC sites.

Therefore, the high activity of $\mathrm{HPC}-\mathrm{M}_{\mathrm{T}}$ is likely due to the hydroxo bridge of HPC which is not only labile but also provides a less steric site for the reactant to approach. The role of the hydroxo bridge in this oxidation reaction may be in the formation of active hydroperoxo species (see also Section 4.5) as shown in
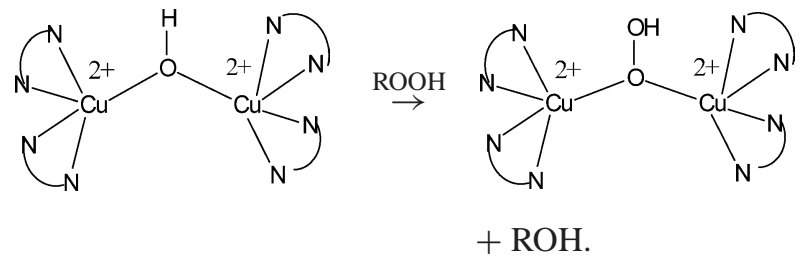

The formation of similar copper-hydroperoxo species during oxidation reaction has been reported [12].

\section{Conclusion}

We have demonstrated that AlMCM-41-supported HPC complexes can be prepared via a simple and direct ionexchange method. Different methods of sample preparation yield products with different surface species and characteristics. HPC- $\mathrm{M}_{\mathrm{T}}$ contains mainly HPC in high concentrations. Monocupric impurity may also be present in the sample, but it was not characterized in detail here [10]. On the other hand, HPC-M $\mathrm{M}_{\mathrm{P}}, \mathrm{HPC} / \mathrm{M}_{\mathrm{PS}}$, and $\mathrm{PN}+\mathrm{CuM}_{\mathrm{T}}$ all have low concentrations of HPC. High concentrations of monocupric complexes may be present in these samples.

The HPC in the channels of MCM-41 can undergo reversible transformation between bridging and nonbridging states as in hemocyanin. In addition, hydroperoxo-bridged dicupric-phenanthroline complexes may be created in situ in MCM-41 from HPC-M $\mathrm{M}_{\mathrm{T}}$ and probably acts as the reactive species for the oxidation of benzyl alcohol.

We further demonstrated the importance of MCM-41 mesopores in these catalysts. The primary function of mesoporous MCM-41 is to provide a confined space (and surface charge) preventing excessive separation of the dicupric center after the hydroxo bridge is removed. This unique property ensures that the bridge can be restored easily. The role played by MCM-41 may serve as the protein skeleton of hemocyanin where two $\mathrm{Cu}^{2+}$ nuclei are fixed in position for proper enzymatic functions. Further applications of HPC immobilized in MCM-41 channels to other catalytic reactions to mimic enzymatic activities are in progress.

\section{Acknowledgments}

This work was supported by a grant from the Ministry of Education through the Academy Excellent program. T.-S. Lin acknowledges partial support by a grant from NSF (INT0115082) and a PRF grant administered by the American Chemical Society (36970).

\section{References}

[1] E.I. Solomon, R.K. Szilagyi, S.D. George, L. Basumallick, Chem. Rev. 104 (2004) 419.

[2] C.R. Jacob, S.P. Varkey, P. Ratnasamy, Appl. Catal. 168 (1998) 353.

[3] E. Armengol, A. Corma, V. Fornes, H. Garcia, J. Prince, Appl. Catal. 181 (1999) 305.

[4] J. Poltowicz, E.M. Serwicka, E. Bastardo-Gonzalez, W. Jones, R. Mokaya, Appl. Catal. 218 (2001) 211.

[5] M.E. Cuff, K.I. Miller, K.E. van Holde, W.A. Hendrickson, J. Mol. Biol. 278 (1998) 855.

[6] E.I. Solomon, F. Tuczek, D.E. Root, C.A. Brown, Chem. Rev. 94 (1994) 827.

[7] K.D. Karlin, R.W. Cruse, Y. Gultneh, A. Farooq, J.C. Hayes, J. Zubieta, J. Am. Chem. Soc. 109 (1987) 2668.

[8] K.D. Karlin, M.S. Haka, R.W. Cruse, G.J. Meyer, A. Farooq, Y. Gultneh, J.C. Hayes, J. Zubieta, J. Am. Chem. Soc. 110 (1988) 1196.

[9] N. Kitajima, K. Fujisawa, Y. Morooka, K. Toriumi, J. Am. Chem. Soc. 111 (1989) 8975.

[10] M.S. Haddad, S.R. Wilson, D.J. Hodgson, D.N. Hendrickson, J. Am. Chem. Soc. 103 (1981) 384. 
[11] S. Chavan, D. Srinivas, P. Ratnasamy, J. Catal. 192 (2000) 286.

[12] K.D. Karlin, R.W. Cruse, Y. Gultneh, J. Chem. Soc., Chem. Commun. (1987) 599.

[13] J.H. Choy, J.B. Yoon, D.K. Kim, S.H. Hwang, Inorg. Chem. 34 (1995) 6524.

[14] J.M. Brown, L. Powers, B. Kincaid, J.A. Larrabee, T.G. Spiro, J. Am. Chem. Soc. 102 (1980) 4210.

[15] K.N. Raymond, D.W. Meek, J.A. Ibers, Inorg. Chem. 7 (1968) 1111.

[16] M. Kurtz, Chem. Rev. 90 (1990) 585.

[17] R.S. Himmelwright, N.C. Eickman, C.D. LuBien, E.I. Solomon, J. Am. Chem. Soc. 102 (1980) 5378.

[18] M.J. Baldwin, D.E. Root, J.E. Pate, K. Fujisawa, N. Kitajima, E.I. Solomon, J. Am. Chem. Soc. 114 (1992) 10421.

[19] P.K. Coughlin, S.J. Lippard, J. Am. Chem. Soc. 103 (1981) 3228.
[20] K.D. Karlin, P. Ghosh, R.W. Cruse, A. Farooq, Y. Gultneh, R.R. Jacobson, N.J. Blackburn, R.W. Strange, J. Zubieta, J. Am. Chem. Soc. 110 (1988) 6769.

[21] H.P. Lin, S.T. Wong, C.Y. Mou, C.Y. Tang, J. Phys. Chem. B 104 (2000) 8967.

[22] J.E. Wertz, J.R. Bolton, Electron Spin Resonance-Elementary Theory and Practical Applications, Chapman \& Hall, New York, 1986.

[23] A. Bencini, D. Gatteschi, EPR of Exchange Coupled Systems, Springer, Berlin, 1990.

[24] D.E. Wilcox, J.R. Long, E.I. Solomon, J. Am. Chem. Soc. 106 (1984) 2186.

[25] P.L. Burk, J.A. Osborn, M.T. Youinou, Y. Agnus, R. Louis, R. Weiss, J. Am. Chem. Soc. 103 (1981) 1273.

[26] J. Xu, J.S. Yu, S.J. Lee, B.Y. Kim, L. Kevan, J. Phys. Chem. B 104 (2000) 1307. 